\title{
Zoopoética cabralina: considerações sobre a questão do animal e da animalidade na poesia de João Cabral de Melo Neto
}

Sérgio Roberto Gomide Filho

Docente do Cefet-MG

Doutorando em Literatura Brasileira do Programa de Pós-Graduação em Estudos Literários /

UFMG

\begin{abstract}
RESUMO
Nas figurações do animal e da animalidade na poesia de João Cabral há uma relação com o ideário estético da pedra, do cálculo, da lucidez. Com base nas especificidades de dois "espaços” da sua poética, Sertão e Andaluzia, discute-se como essas figurações ajudam a compreender melhor 0 cerebralismo do autor.
\end{abstract}

\section{PALAVRAS-CHAVE}

João Cabral de Melo Neto, poesia brasileira, animais, animalidade

À primeira vista, um estudo sobre as figurações do animal e da animalidade na poesia de João Cabral poderia parecer uma tarefa dedicada a questões secundárias, à margem das conhecidas diretrizes mobilizadas (e verbalizadas) pelo poeta em seu processo de composição. Poesia da pedra, poeta da lucidez. E a lucidez, poderíamos logo pensar, estaria para a noção de animalidade assim como o ideário da pedra para a noção de animal, numa relação de clara prevalência e, não raro, acentuada oposição. O animal mineraliza-se; por sua vez, a animalidade ameaça, mas como que sucumbe diante do controle racional da expressão:

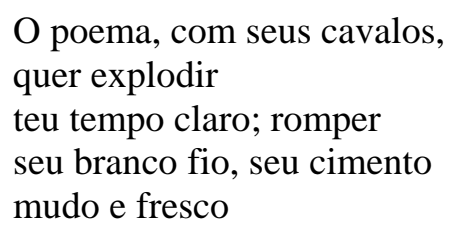

São minerais as flores e as plantas, 
as frutas, os bichos

quando em estado de palavra.

(...)

onde foi palavra

(potros ou touros

contidos) resta a severa

forma do vazio. ${ }^{1}$

No entanto, um segundo olhar sobre o estatuto do animal e da animalidade sugere, para além da simples oposição, uma relação constitutiva com o ideário da pedra, do cálculo, da lucidez. Uma relação oblíqua, de fato, mas que se projeta sobre as principais diretrizes poéticas de João Cabral e recobre questões que se situam na esfera do próprio ato de criação.

De imediato, convém pontuar algumas importantes diferenças entre dois "espaços" fundamentais na poesia de João Cabral, já que, em razão dessa diferença, as figurações do animal e da animalidade podem variar significativamente: Nordeste e Espanha; ou mais especificamente, Pernambuco e Andaluzia, Sertão e Sevilha. Trata-se, na verdade, de espaços muito mais abrangentes do que a representação geográfica que os circunscreve. Não por acaso, em uma “autocrítica” a seu modo, na terceira pessoa, o poeta certa vez atribuiu a esses dois lugares a razão de ser de sua poesia:

\section{Só duas coisas conseguiram (des)feri-lo até a poesia: o Pernambuco de onde veio e o aonde foi, a Andaluzia. Um, o vacinou do falar rico e deu-lhe a outra, fêmea e viva, desafio demente: em verso dar a ver Sertão e Sevilha. ${ }^{2}$}

Como se nota desde já, ao passo que o espaço andaluz endereça um desafio à escrita, o espaço sertanejo impõe-se sobre o modo de expressão. E diferentemente dos poemas de matizes sevilhanos, que, em geral, ativam uma dimensão erótico-passional afim à animalidade "fêmea e viva" - como se percebe nos versos acima e se discutirá melhor mais adiante -, nos poemas de temática sertaneja, a questão do animal tende, como a própria linguagem mobilizada pelo poeta, a apresentar-se sob o signo da privação, em correspondências com a

\footnotetext{
${ }^{1}$ MELO NETO. Poesia completa e prosa, p. 70-73.

${ }^{2}$ MELO NETO. Poesia completa e prosa, p. 430.
} 
precariedade do espaço geográfico e social. Assim, a paisagem desértica, asséptica e esterilizante do Sertão (que equivale a todo um ideário poético do pétreo e inorgânico), quando não suprime a possibilidade mesma da vida, incide fortemente sobre as condições de existência de todos os seres que a habitam. E, sob esse aspecto, o mesmo poderia ser dito em relação à paisagem contida dos mangues, ou ainda em relação às praias pernambucanas, outros dois espaços nordestinos caros ao poeta.

Tendo em vista algo da ordem de uma zoopoética nesses diferentes cenários, podemos examinar as figurações do animal acompanhando o percurso dos rios cabralinos, do Sertão ao mar - especialmente o Capibaribe, que em um longo poema de 1953 relata em primeira pessoa a viagem que faz de sua nascente à cidade do Recife. O Sertão, no caso, é sua infância:

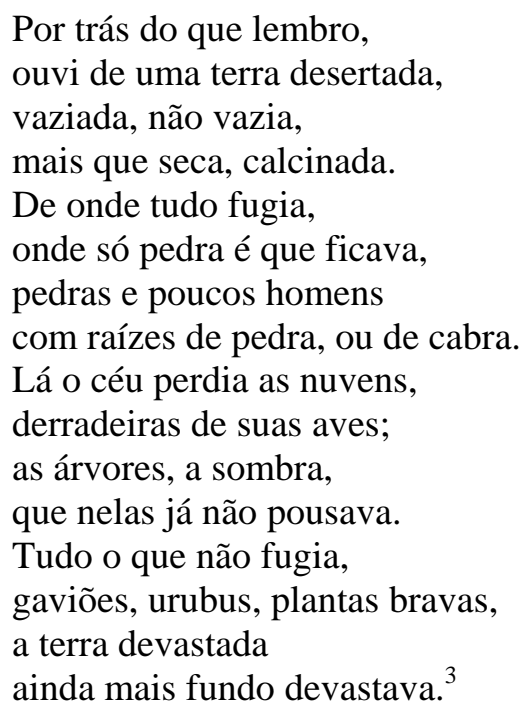

Esse trecho resume bem as condições de existência no inóspito e calcinado cenário sertanejo e é paradigmático de ao menos três particularidades complementares relativas às figurações que o animal aí assume: (i) resto, ruína do que a terra desertou e devastou; (ii) justamente por isso, elemento central da crítica sócio-histórica que se formula à luz da “condição de bicho” do homem sertanejo; (iii) mas também signo de resistência e insubordinação, com o qual o fazer poético estabelece relações de identificação e aprendizado.

No Sertão do poeta, a cabra talvez seja o animal que melhor traduz essas particularidades. E a despeito de todo esforço de impessoalidade de João Cabral, em vista de sua obstinada poesia do objeto, avessa ao eu, não é demais lembrar que a cabra liga-se ao

\footnotetext{
${ }^{3}$ MELO NETO. Poesia completa e prosa, p. 96.
} 
próprio sobrenome do poeta. Parafraseando livremente Jacques Derrida, ${ }^{4}$ poderíamos dizer que se trata de um caso bastante particular de um "animal autobiográfico”: étimo de um nome próprio, síntese de uma poética; a um só tempo, índice de despersonalização e rastro do eu.

Veja-se, por exemplo, o caso de “Poema(s) da cabra”, em que a cabra das margens pedregosas (mas nobres) do Mediterrâneo é contraposta à cabra nordestina, esta apresentada como o ponto de inflexão da analogia que integra a crítica às condições inumanas do Sertão. ${ }^{5}$ Por um lado, “condenada à caatinga seca”, por outro, resistente e insubordinada. Disso decorre um movimento como que oposto ao da fábula: é a cabra que empresta ao sertanejo seus atributos. "O nordestino, convivendo-a / fez-se de sua mesma casta (...) A cabra deu ao nordestino / esse esqueleto mais de dentro: o aço do osso, que resiste / quando o osso perde seu cimento.”6 Esse ensinamento, por sua vez, em nada lembra os preceitos morais, tão comuns na fábula tradicional. ${ }^{7} \mathrm{O}$ que a cabra representa em termos éticos é o que representa em termos estéticos, o que ela "ensina” ao nordestino é também sua lição de poética: a interioridade concreta e exteriorizada, sua "alma-caroço”, “apenas côdea”, seu "núcleo visível” por baixo das coisas e dos homens; sua capacidade de chegar aonde nada chega e resistir onde tudo é pedra, sede e fome; seu áspero realismo, sem contemplações, sem “o grosso derrame do porco, da vaca, de sono e de tédio”. Estamos diante de uma "educação pela cabra”, plenamente identificada ao ideário da pedra (e às imagens de si construídas pelo poeta).

E de volta ao (dis)curso dos rios cabralinos, encontramos nos canaviais particularidades não menos instigantes. Muito frequentemente associado ao mar, o canavial também é deserto e, dependendo do ponto de vista, ainda mais inóspito do que o Sertão, apesar do verde. Espaço conflituoso de tensão ideológica e decadência histórica, nele não há "bicho com vida”, mas "vida bichada”. No entanto, como ocorre com o Sertão, o mesmo canavial que oprime e suprime a vida é também fonte de aprendizagens poéticas - e não são poucos os exemplos nesse sentido, a começar pelo próprio ideal de “desertificação”. E aqui nos deparamos mais uma vez com a esquiva dimensão do sujeito intercalando-se com as figurações do animal: mesmo na paisagem desertificada dos canaviais, encontramos imagens

\footnotetext{
${ }^{4}$ DERRIDA. O animal que logo sou (A seguir).

${ }^{5}$ Esse texto dialoga abertamente com o poema "La chèvre", de Francis Ponge; daí a contraposição entre Mediterrâneo e Nordeste.

${ }^{6}$ MELO NETO. Poesia completa e prosa, p. 234. (grifos do autor)

${ }^{7}$ Outros exemplos de desvirtuamento da fábula podem ser encontrados ao longo da obra do poeta, especialmente em A educação pela pedra. É o caso de "O urubu mobilizado" e de "The country of the houyhnhms”, este último parafraseando a sátira de Swift.
} 
do pássaro associadas a uma verdadeira obsessão do poeta (senão de todo poeta e da própria poesia): a percepção do tempo que escapa, do que decorre a tentativa de sua contenção, bem como de sua apreensão tácita no espaço deserto. No caso, os pássaros corporificam a percepção auditiva, a voz, a linguagem do tempo:

Do ermo que vai em derredor, das várzeas de cana somente, passarinhos buscando pouso vêm aterrissar neste alpendre.

Onde cada um com a receita herdada dentro da família, se põe a demonstrar que o tempo não soa sempre em água lisa.

O tempo então é mais que coisa: é coisa capaz de linguagem, e que ao passar vai expressando as formas que tem de passar-se

Patativas, papa-capins, xexéus, concrises, curiós: é então que se escuta o tempo que passa e o diz, de viva voz.

Sabiás, canários-da-terra, cantando de estalo e corrido: uns gaguejando, qual telégrafo, outros contínuos, como um trilho.

Sanhaçus, galos-de-campina, ferreiros, com ferro no estilo: todos vêm mostrar como passa, em sintaxes de todo tipo,

o tempo que de nós se perde sem que lhe armemos alçapão nem mesmo agora que parece passar ao alcance da mão, nem mesmo agora que chegou tão perto, tão familiarmente, certo atraído pela sesta avarandada deste alpendre. ${ }^{8}$

A associação entre pássaro e tempo é comum na poesia de João Cabral, como, por exemplo, nas imagens do relógio como "gaiola de pássaro”, com sua “alada palpitação”, em poemas como “O relógio” e "Uma faca só lâmina”, ou ainda, em um sentido um pouco distinto, como nos versos de encerramento de “O cão sem plumas”, na comparação entre "a vida que se luta cada dia” e a ave "que vai cada segundo conquistando seu vôo”.

\footnotetext{
${ }^{8}$ MELO NETO. Poesia completa e prosa, p. 322-323.
} 
Porém, no poema acima citado, o que chama a atenção é o modo com que essa relação entre pássaro e tempo se manifesta. Para além da metáfora, atribui aos pássaros um saber e ao poeta, um aprendizado. E, o que é ainda mais significativo, saber e aprendizado apresentam-se em termos de linguagem. Nesse sentido, sob uma perspectiva agambiana, poderíamos supor que, se o tempo “é coisa capaz de linguagem”, se essa linguagem é a “viva voz” dos pássaros, se o tempo, como o pássaro, é o que "de nós se perde”, mesmo quando "parece passar ao alcance da mão”, então, em última análise, o que os pássaros ensinam é que não apenas o tempo, mas a própria linguagem que nele se inscreve é o que foge, o que escapa ao poeta. ${ }^{9}$

Seguindo o curso dos rios que seguem dos canaviais em direção aos mangues, encontramos particularidades não muito diferentes quanto à supressão do que vive, ainda que, comparado ao Sertão, trate-se de um espaço em si mesmo animalizado, de fecundidade e mesmo certa feminilidade, “do cio e da prenhez da maré”. Como ocorre no cenário sertanejo, as figurações do animal tendem a destacar a "condição de bicho” do homem, como se percebe na seguinte passagem de "Morte e vida severina", em que uma cigana lê o futuro da criança franzina recém-nascida:

Vou dizer todas as coisas
que desde já posso ver
na vida desse menino
acabado de nascer:
aprenderá a engatinhar
por aí, com aratus,
aprenderá a caminhar
na lama, com goiamuns,
e a correr o ensinarão
os anfíbios caranguejos,
pelo que será anfíbio
como a gente daqui mesmo.
Cedo aprenderá a caçar:
primeiro, com as galinhas,
que é catando pelo chão

${ }^{9}$ Com sua noção de infância, Giorgio Agamben inverte o paradigma da diferença entre humanos e animais, no que tange à linguagem. Os animais, diferentemente do que usualmente se pensa, "não são destituídos de linguagem; ao contrário, eles são sempre e absolutamente língua (...). Os animais não entram na língua: já estão sempre nela. O homem, ao invés disso, na medida em que tem uma infância, em que não é já sempre falante, cinde esta língua una e apresenta-se como aquele que, para falar, deve constituir-se como sujeito da linguagem, deve dizer eu." (AGAMBEN. Infância e história: destruição da experiência e origem da história, p. 63-64, grifo do autor.) O homem, nesse sentido, não seria propriamente "o falante", distinguindo-se sob tal aspecto dos animais, como se propôs ao longo de toda uma tradição filosófica, mas, sim, um ser primordialmente privado de voz, um infante, literalmente, desprovido de fala. A voz humana seria como um "animal em fuga", cuja busca equivaleria ao pensamento. "O pensamento", diz Agamben, "é a pendência da voz na linguagem”. Quanto a uma articulação possível com o poema de João Cabral, vale lembrar ainda a mesma raiz etimológica entre pendência e alpendre. 
tudo o que cheira a comida;

depois, aprenderá com

outras espécies de bichos:

com os porcos nos monturos,

com os cachorros no lixo. ${ }^{10}$

Nesse trecho, os traços de uma perspectiva fabular novamente são invertidos, dessa vez no contexto do desvirtuamento da narrativa cristã (trata-se de um "auto de Natal pernambucano”). Mais enfática do que a antropomorfização do bicho é a animalização do homem. Na relação humano/não humano, os saberes mantêm-se no polo do animal, mas apresentam-se em função do homem, isto é, em função da desumanidade a que, no fundo, esse “deslocamento” de saberes alude. O que está em jogo, podemos supor, não é propriamente o que os animais "sabem”, mas a deteriorada situação humana em face à metáfora dessa aprendizagem.

Em “O cão sem plumas” dá-se algo um pouco diverso. A metáfora do animal é pormenorizadamente trabalhada, também em termos de privação, em reciprocidade com a precariedade geográfica, social e histórica. O rio é um “cão sem plumas”, termo de uma comparação desmembrada em uma série de significações distintas, indicativas de indigência, miséria, penúria. Rio que “jamais se abre aos peixes”, “jamais se abre em peixes”; rio que "nada sabia dos peixes de água”: "Sabia dos caranguejos / de lama e ferrugem (...) Devia saber dos polvos. / Sabia seguramente / da mulher febril que habita as ostras.”11

O espaço do mangue é da ordem do desfalque, da subtração, da falta do mínimo necessário ao que vive, e a escrita indica em si mesma esse espaço de corrosão:

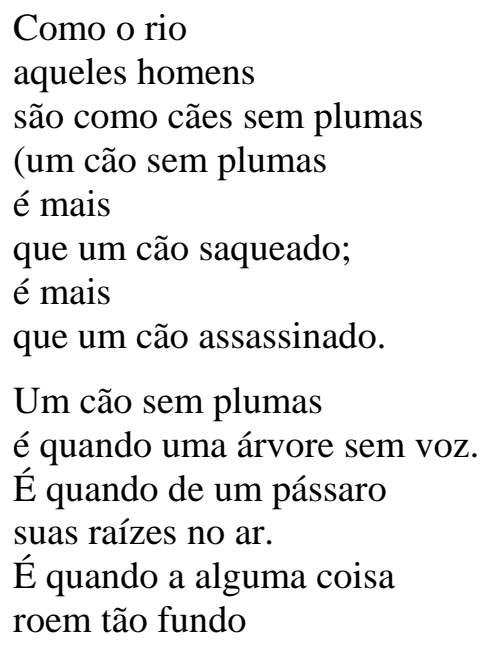

\footnotetext{
${ }^{10}$ MELO NETO. Poesia completa e prosa, p. 174.

${ }^{11}$ MELO NETO. Poesia completa e prosa, p. 81-82.
} 
até o que não tem). ${ }^{12}$

A designação "sem plumas”, pela ênfase na falta, relaciona “rio”, “cão” e "homem”. Essa falta está na disposição gráfica, sintática e simbólica do poema e é por ela que o discurso poético, roído e sem ornamentos faz referência a si: contra a "linguagem emplumada”, "sem plumas” é a própria escrita cabralina, porque nada é enfeite na paisagem de que se fala. A pertinência dessa codesignação, por sua vez, sugere que, entre o rio, cão desemplumado, e o fazer poético, existe uma identificação mútua, ainda que estabelecida pela falta e pela perda. E contrariando todas as probabilidades, assim como se dá no cenário sertanejo, há algo que resiste na condição de resto: seja a vida nos mangues, seja a possibilidade da palavra poética.

No mangue, rio e mar se confundem, mas quando, por fim, o poeta toma por objeto o mar propriamente dito, as figurações do animal tendem a ser semelhantes àquelas do Sertão. Sob um sol implacável, o mar é ácido, a areia, asséptica. E sob tais condições, o mar, apesar da água, adquire a mesma lógica poética da pedra:

Nas praias do Nordeste, tudo padece
com a ponta de finíssimas agulhas:
primeiro, com a das agulhas da luz
(ácidas para os olhos e a carne nua),
fundidas nesse metal azulado e duro
do céu dali, fundido em duralumínio,
e amoladas na pedra de um mar duro,
de brilho peixe também duro, de zinco.
Depois com a ponta das agulhas do ar,
vaporizadas no alíseo do mar cítrico,
desinfetante, fumigando agulhas tais
que lavam a areia do lixo e do vivo. ${ }^{13}$

Significativamente diferentes são as figurações do animal e da animalidade nos “poemas espanhóis” de João Cabral, mais especificamente naqueles em que uma dimensão erótico-passional encontra-se em destaque - o que ocorre não apenas nos textos que abordam as imagens do feminino, mas também naqueles que, partindo de um espaço erotizado, tomam por objeto a própria atividade poética.

É o que podemos notar, logo de início, em um poema como "Estudos para uma bailadora andaluza”. Na comparação entre mulher e égua, a complementaridade da relação

\footnotetext{
${ }^{12}$ MELO NETO. Poesia completa e prosa, p. 84.

${ }^{13}$ MELO NETO. Poesia completa e prosa, p. 324.
} 
entre humano e animal aponta para sentidos bem diversos do que aqueles suscitados pelos poemas nordestinos, nos quais essa complementaridade tende a ser estabelecida pela falta:

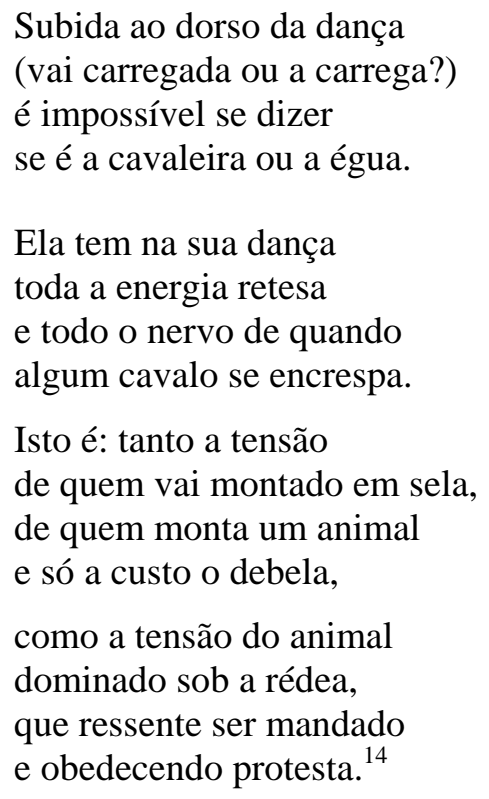

Aqui, ao contrário do que ocorre nos poemas pernambucanos, a complementaridade entre humano e animal vem marcada por um excesso - de tensão, força, erotismo. ${ }^{15} \mathrm{E}$, sob essa mesma ótica, ao passo que a indistinção entre "nordestino" e "animal” alude quase sempre à precariedade do ser humano, em sua "condição de bicho", aqui a animalidade é tomada em um sentido positivo e, ao mesmo tempo, aporético: “é impossível se dizer”, não há “como declarar” a diferença entre o que doma e o que é domado.

$$
\begin{aligned}
& \text { Então, como declarar } \\
& \text { se ela é égua ou cavaleira: } \\
& \text { há uma tal conformidade } \\
& \text { entre o que é animal e é ela, } \\
& \text { entre a parte que domina } \\
& \text { e a parte que se rebela, } \\
& \text { entre o que nela cavalga } \\
& \text { e o que é cavalgado nela, } \\
& \text { que o melhor será dizer } \\
& \text { de ambas, cavaleira e égua, } \\
& \text { que são de uma mesma coisa } \\
& \text { e que um só nervo as inerva, } \\
& \text { e que é impossível traçar }
\end{aligned}
$$

\footnotetext{
${ }^{14}$ MELO NETO. Poesia completa e prosa, p. 196.

${ }^{15}$ Excesso subtrativo, poderíamos pensar. De fato, esse aspecto, que já foi bastante examinado pela crítica do poeta, encontra-se, por exemplo, na base da tese de Antonio Carlos Secchin, segundo a qual a poesia cabralina "se constrói sob o prisma do menos". (SECCHIN. João Cabral: a poesia do menos e outros ensaios, p. 15.)
} 
nenhuma linha fronteira

entre ela e a montaria:

ela é a égua e a cavaleira. ${ }^{16}$

Essa tangência entre erotismo, animalidade e expressão poética pode ser notada também em outro poema bastante conhecido de João Cabral. Em “A palavra seda”, conduz igualmente ao estatuto da palavra poética:
A atmosfera que te envolve atinge tais atmosferas que transforma muitas coisas que te concernem ou cercam.
E como as coisas, palavras impossíveis de poema: exemplo, a palavra ouro, e até este poema, seda.
É certo que tua pessoa não faz dormir, mas desperta; nem é sedante, palavra derivada da de seda.
E é certo que a superfície de tua pessoa externa, de tua pele e de tudo isso que em ti se tateia, nada tem da superfície luxuosa, falsa, acadêmica, de uma superfície quando se diz que ela é "como seda", ${ }^{17}$

Essa recusa aos significados "líricos” do termo "seda” culmina na recuperação de sua significação animal, etimológica. Na palavra "seda”, a animalidade, o “bicho-da-seda" persiste e é daí que parte a comparação com a figura feminina:

Mas em ti, em algum ponto, talvez fora de ti mesma, talvez mesmo no ambiente que retesas quando chegas há algo de muscular, de animal, carnal, pantera, de felino, da substância felina, ou sua maneira, de animal, de animalmente, de cru, de cruel, de crueza, que sob a palavra gasta

\footnotetext{
${ }^{16}$ MELO NETO. Poesia completa e prosa, p. 196.

${ }^{17}$ MELO NETO. Poesia completa e prosa, p. 222.
} 


$$
\text { persiste na coisa seda. }{ }^{18}
$$

Que, na poesia de João Cabral, essa intercorrespondência entre animal, animalidade e erotismo projete-se sobre o próprio fazer poético, demonstram-no ainda mais claramente as diversas passagens dedicadas às imagens do touro, nas quais é possível identificar mais um traço marcante da presença andaluza em sua obra: “fazer no extremo, onde o risco começa”, como dizia o poeta em “Coisas de cabeceira: Sevilha”. O que mais uma vez aponta para a dimensão do sujeito, diante do desafio de sondar os limites da escrita e se expor (por esquiva) no que se escreve - como na atividade de um toureiro que, com o mínimo de movimento, busca conter a força indomável do touro.

O fascínio que as touradas exerceram em João Cabral, desde sua primeira estadia na Espanha, disseminou-se ao longo de toda sua obra. Para o poeta pernambucano, as touradas continham um modelo de poética. Em carta a Manuel Bandeira, em setembro de 1947, João Cabral, iniciando-se nas artes tipográficas, relatava seu projeto, nunca concluído, de organizar uma antologia com poemas sobre as "corridas de touros". Alguns trechos da carta são esclarecedores: "Faz hoje uma semana que um [touro] miúra matou Manolete, considerado o melhor toureiro que já aparecera até hoje. - Seja dito de passagem que era um camarada fabuloso: vi-o algumas vezes aqui em Barcelona e imaginei que era Paul Valéry toureando.”19 Nesse mesmo ano, a imagem do "touro contido" aparece nos versos finais de "Psicologia da composição”. Menos de 10 anos depois, a lembrança de Manolete seria transformada em lição de poesia:

\footnotetext{
Mas eu vi Manuel Rodríguez, Manolete, o mais deserto, o toureiro mais agudo, mais mineral e desperto

(...)

o que melhor calculava

o fluido aceiro da vida, o que com mais precisão roçava a morte em sua fímbria, o que à tragédia deu número, à vertigem, geometria, decimais à emoção e ao susto, peso e medida sim, eu vi Manuel Rodríguez, Manolete, o mais asceta,
}

\footnotetext{
${ }^{18}$ MELO NETO. Poesia completa e prosa, p. 222.

${ }^{19}$ MELO NETO. Poesia completa e prosa, p. 34.
} 
não só cultivar sua flor

mas demonstrar aos poetas:

Como domar a explosão

com mão serena e contida,

sem deixar que se derrame

a flor que traz escondida,

e como, então, trabalhá-la

com mão certa, pouca e extrema:

sem perfumar sua flor,

sem poetizar seu poema. ${ }^{20}$

Lições semelhantes podem ser encontradas em poemas de Agrestes ("Lembrando Manolete”) e de Andando Sevilha, o último livro publicado pelo poeta ("Manolo González" e “Miguel Baez, 'Litri’”). São lições constitutivas do fazer literário cabralino e, nelas, pode-se perceber a relação entre o chifre do touro e a faca, outro elemento central na poesia de João Cabral: ambos são forças indomáveis com as quais o poeta/toureiro deve lidar no instante extremo da criação, sem floreios, sem lirismo, contando apenas com a primazia da técnica sobre a força bruta. ${ }^{21}$ A sagacidade técnica e a indomabilidade, portanto, estão em mútua correspondência. Veja-se, no poema acima, o lado oposto do cálculo, da precisão, do número, da geometria... O lado do touro, fluido aço da vida: tragédia, vertigem, emoção, susto, morte.

A aproximação entre a criação literária e o duelo contra o touro marca a célebre proposição de Michel Leiris, em “Da literatura como tauromaquia”, texto de abertura de seu livro de memórias. Independentemente do fato de João Cabral conhecê-la ou não, a questão colocada logo de início pelo escritor francês poderia ter sido conceitualmente formulada pelo poeta pernambucano:

Será que o que se passa no domínio da escrita não é desprovido de valor se permanecer "estético", anódino, privado de sanção, se nada houver, no fato de escrever uma obra, que seja equivalente (...) daquilo que é para o torero o chifre acerado do touro, capaz de conferir - em razão da ameaça material que contém - uma realidade humana à sua arte, de impedir que ela seja apenas encantos fúteis de bailarina? ${ }^{22}$

\footnotetext{
${ }^{20}$ MELO NETO. Poesia completa e prosa, p. 133-134.

${ }^{21}$ O poema "Diálogo", incluído em Paisagens com figuras, talvez seja o exemplo mais esclarecedor da relação entre a tauromaquia, a faca e o cante andaluz: "mas o timbre desse canto / que acende na própria alma / o cantor da Andaluzia / procura-o no puro nada, / como à procura do nada / é a luta também vazia / entre o toureiro e o touro, / vazia, embora precisa, / em que se busca afiar / em terrível parceria / no fio agudo de facas / o fio frágil da vida.” (MELO NETO. Poesia completa e prosa, p. 139.)

${ }^{22}$ LEIRIS. Da literatura como tauromaquia, p. 16.
} 
Não menos sugestiva é a proximidade entre o "chifre do touro", tal como Leiris o concebe, e a faca de João Cabral: em ambos os casos, o que está em jogo é uma obsessão e a necessidade de olhá-la de frente, aceitando o risco de exposição que ela representa para o ato da palavra. ${ }^{23}$

Como bem mostram os versos de "Psicologia da composição" citados no início deste artigo, essas questões tauromáquicas apresentam-se também nas figurações do cavalo, como metáfora do que, na criação poética, não se pode contido, por mais que a lucidez se mantenha vigilante. É o que encontramos, por exemplo, em "Fábula de Anfion”, no fracasso do personagem mitológico, antes de lançar sua flauta aos “peixes surdos-mudos do mar”:

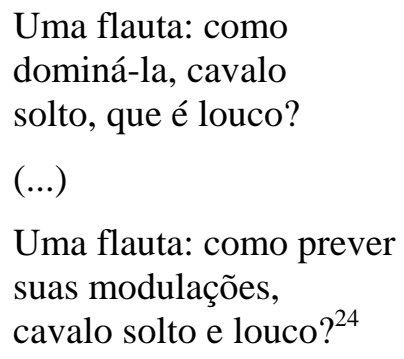

E mais de 30 anos depois, a mesma questão reapareceria no poema de abertura de $A$ escola das facas:

$$
\begin{aligned}
& \text { Um poema é sempre, como um câncer: } \\
& \text { que química, cobalto, indivíduo } \\
& \text { parou os pés desse potro solto? } \\
& \text { Só o mumificá-lo, pô-lo em livro. }
\end{aligned}
$$

Como se vê, diante do ideário da pedra e da lucidez, as figurações do animal e da animalidade suscitam questões que ajudam a compreender melhor o próprio cerebralismo de João Cabral, pois, ao mesmo tempo em que evidenciam as relações entre o exercício da racionalidade e a construção poética, revelam que, em última análise, há, na poesia, algo que sempre escapa à razão.

${ }^{23}$ A leitura que Blanchot faz do prefácio de Leiris merece ser destacada por sua potencial correspondência com o projeto cabralino: "Escrever não é nada, se escrever não transporta o escritor num movimento cheio de riscos que o transformará de uma maneira ou de outra. Escrever é apenas um jogo sem valor, se esse jogo não se tornar uma experiência aventureira em que aquele que a faz, engajando-se num caminho cujo fim ignora, pode aprender o que não sabe e perder o que o impede de saber. E, depois, escrever, sim, mas se escrever tornar sempre mais difícil o ato de escrever, tende a lhe retirar as facilidades que as palavras sempre recebem das mãos mais hábeis.” (BLANCHOT. A parte do fogo, p. 236.)

${ }^{24}$ MELO NETO. Poesia completa e prosa, p. 68.

${ }^{25}$ MELO NETO. Poesia completa e prosa, p. 391. 
João Cabral disse certa vez que o "símbolo da poesia” deveria se r não “o Pégaso, o cavalo que voa”, mas a galinha, que tem asas mas não voa. ${ }^{26}$ Com base na própria obra do poeta, poderíamos reformular tal anedota e tomar como "símbolo" de sua poesia um animal igualmente "rasteiro” e antipoético: o ouriço, na verdade, “uma ouriça”:

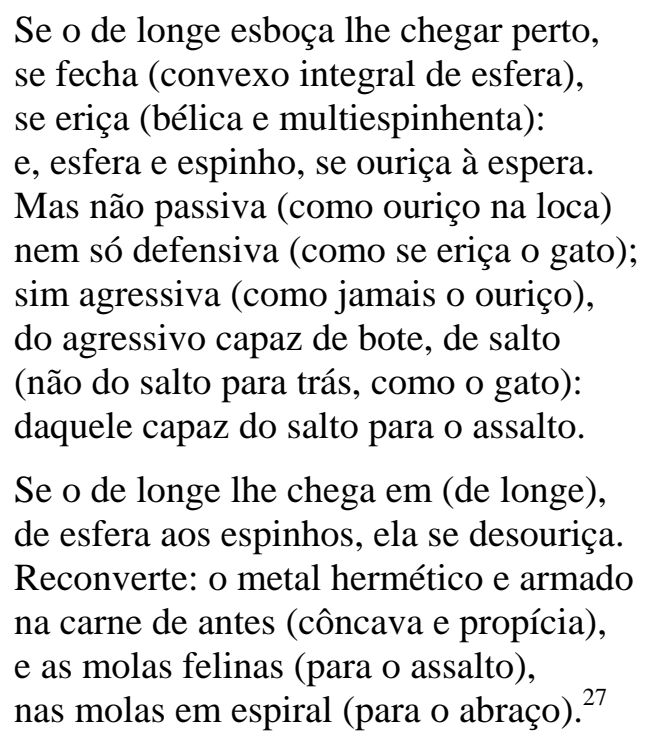

Ainda que o poema, a princípio, tenha em vista a composição de uma agressiva e erotizada figura feminina - esta, diga-se de passagem, mais uma vez apresentada sob o signo da animalidade - a metáfora poética não deixa de ser pertinente, especialmente quando se tem em vista as questões discutidas ao longo deste artigo. E é interessante notar que a metáfora, nesse caso, coincidiria, de modo sugestivo, com a imagem proposta por Derrida, ${ }^{28}$ em "Che cos’è la poesia?”: “Não a fénix, não a águia, [mas] o ouriço, muito baixo, bem baixo, próximo da terra.” No poema de João Cabral, uma “ouriça”: não se pode segurá-la nas mãos; ela é acessível somente a certa distância; ao mesmo tempo, é capaz de fazer do ataque abraço, da agressão acolhimento. Capaz de desarmar. E desarmar-se.

Nesse sentido, vale notar que, enquanto metáfora da própria poesia, o termo “ouriço" recuperaria, etimologicamente, a noção de cavalo, pelo grego ekhínos, equino. Meta-zoopoética: eis o ponto em que, na poesia de João Cabral, o dizer contra torna-se contradição.

\footnotetext{
${ }^{26}$ MELO METO citado por ATHAYDE. Idéias fixas de João Cabral de Melo Neto, p. 72.

${ }^{27}$ MELO NETO. Poesia completa e prosa, p. 320.

${ }^{28}$ DERRIDA. Che cos’è la poesia?
} 


\begin{abstract}
Figurations of animal and animality in João Cabral de Melo Neto’s poetry are related to his aesthetic ideas about stones, calculus, and lucidity. An analysis based on the two "spaces" of Sertão/Pernambuco and Andalusia enables us to understand better his cerebral approach to poetry and prose.
\end{abstract}

\title{
KEYWORDS
}

João Cabral de Melo Neto, Brazilian poetry, animals, animality

\section{REFERÊNCIAS}

AGAMBEN, Giorgio. Infância e história: destruição da experiência e origem da história. Trad. Henrique Burigo. Belo Horizonte: Editora UFMG, 2005.

AGAMBEN, Giorgio. A linguagem e a morte: um seminário sobre o lugar da negatividade. Trad. Henrique Burigo. Belo Horizonte: Editora UFMG, 2006.

ATHAYDE, Félix de. Idéias fixas de João Cabral de Melo Neto. Rio de Janeiro: Nova Fronteira: FBN; Mogi das Cruzes, SP: Universidade de Mogi das Cruzes, 1998.

BLANCHOT, Maurice. A parte do fogo. Trad. A. M. Scherer. Rio de Janeiro: Rocco, 1997.

DERRIDA, Jacques. Che cos'è la poesia? Trad. Tatiana Rios e Marcos Siscar. Inimigo Rumor 10, Rio de Janeiro, 7 letras, p. 113-116, maio 2001.

DERRIDA, Jacques. O animal que logo sou (A seguir). Trad. Fábio Landa. São Paulo: Unesp, 2002.

LEIRIS, Michel. Da literatura como tauromaquia. In: . A idade viril. Trad. Paulo Neves. São Paulo: Cosac \& Naify, 2003. p.13-26.

MELO NETO, João Cabral. Correspondência de Cabral com Bandeira e Drummond. Organização, apresentação e notas Flora Süssekind. Rio de Janeiro: Nova Fronteira, Fundação Casa de Rui Barbosa, 2001.

MELO NETO, João Cabral. Poesia completa e prosa. Org. Antonio Carlos Secchin. Rio de Janeiro: Nova Aguilar, 2008.

SECCHIN, Antonio Carlos. João Cabral: a poesia do menos e outros ensaios cabralinos. Rio de Janeiro: Topbooks, 1999. 